\title{
TRENDS IN RENAL STONE CLEARANCE AFTER URETEROSCOPY: A REVIEW
}

\author{
Subiksha Subramonian ${ }^{1}$, Somasundari Gopalakrishnan ${ }^{2}$, Yuko Smith $^{3}$ \\ ${ }^{1}$ University of Cambridge. \\ ${ }^{2}$ Liverpool School of Tropical Medicine. \\ 3University of Birmingham.
}

Corresponding author: subisubramonian@gmail.com

Submitted: September 27, 2019. Accepted: October 9, 2019. Published: December 23, 2019.

\begin{abstract}
Background and Objectives

Stone clearance rate in ureteroscopy has varied over the years. This study aims to review the stone clearance rate over the last 25 years and assess the change over time. We have analyzed the reasons for the peaks and troughs in stone clearance rate to see if it correlates with any factors such as the introduction of new technology like the holmium laser, flexible ureteroscopy, access sheaths, and digital ureteroscopy.
\end{abstract}

\section{Material and Methods}

We performed a PubMed search (August 2019) for papers including the terms "lithiasis", "stone clearance", "calculi", "kidney stone", "ureteric stone", "ureteroscopy", "holmium laser", "retrorenal surgery" in their title and published between the years 1994 and 2019. The stone size, stone clearance rate and mode of imaging to determine clearance rates were recorded. For data analysis, only prospective studies with a minimum of 50 patients and ureteroscopy arm of prospective randomized controlled trials were included.

\section{Results}

We reviewed 16 papers with a total of 1,689 patients with renal stones. Average stone clearance was $80 \%$ and the median stone size was $11.0 \mathrm{~mm}$. Stone clearance was determined by either: Computed tomography (CT) scan (8 studies), x-ray alone (3 studies), x-ray and ultrasound (3 studies) or not mentioned (2 studies). $\mathrm{CT}$ scan yielded lower stone clearance rates than $\mathrm{x}$-ray due to the increased detail shown on CT. For studies that used absolute clearance with no residual stones, average clearance was $52 \%$, and this stone clearance rate increased as the cut-off size used to determine the stone-free rate was increased.

\section{Conclusion}

This study highlights that stone clearance rate after ureteroscopy varies significantly amongst different papers because of the stone size used to define 'stone-free rate' and the method of imaging used to determine stone clearance. The study also shows that stone clearance rates have not improved significantly over time, despite the introduction of advances in technology.

Key Words: renal stones, ureteroscopy, stone clearance

J Endolum Endourol Vol 2(4):e44-e50 December 23, 2019.

This article is distributed under the terms of the Creative Commons Attribution-Non

Commercial 4.0 International License. (C) Subramonian et al. 
Ureteroscopy has been popular since the 1980s for both diagnosis of intra-renal conditions and removal of stones from the kidney and ureter. Since the rigid ureteroscope was first introduced in 1980, we have seen many technological advances (shown in Table 1) in the design and size of the scopes, energy sources used to break the stone, retrieval baskets, access methods, development of new techniques and training imparted to surgeons.

Parallel to the endoscopic developments, we have seen shifts in radiological practice with improvement in resolution of ultrasound and $\mathrm{CT}$; digital image processing and the widespread awareness of "ALARP" (as low as reasonably practical) to imaging choices.

Other factors that could have affected stone clearance rates are:

1.Introduction of smaller and sophisticated ureteroscopes.

2. Newer and more powerful technologies to break stones

3. Better training of surgeons

4. Introduction of alternative treatments such as mini PCNLs which reduced the size of stones treated by lithotripsy

5. Stones becoming easy to break

The main outcome measure of whether a ureteroscopy has been successful is the stone clearance rate achieved. There have been several studies, which have addressed this outcome over the years.

In this study, we have reviewed the stone clearance rate in ureteroscopy for renal stones over the last 25 years. We have also reviewed the technological advances in the field of ureteroscopy and stone removal and assessed the factors that could determine the stone clearance rate.

\section{METHODS}

We performed a PubMed search (August 2019) for papers including the terms "lithiasis", "stone clearance", "calculi,", "kidney stone", "ureteric stone", "ureteroscopy", "holmium laser", "retrorenal surgery" in their title and published between the years 1994 and 2019 .

(lithiasis) OR stone clearance) OR calculi) OR kidney stone) OR ureteric stone) AND ureteroscopy) OR holmium laser) OR retrorenal surgery) NOT eye) NOT ophthalmology) NOT YAG) NOT dermatology) NOT cosmetology) NOT plastics

Moreover, key papers and other important studies on the subject were also included and cross-referenced, if they were considered noteworthy. The authors adhered to PRISMA guidelines for this review. All relevant data were identified, selected, and summarized below.

For data analysis, only prospective studies with a minimum of 50 patients were included (except for two papers which had such high-quality data, that we included them despite their small sample size). Ureteroscopy arms of prospective randomized controlled trials were also included. Year and Country of publication, journal and impact factor and study period was noted. After the initial search, we decided to only review papers on renal stones (excluding ureteric stones) to ensure that the stone clearance rates were reported accurately and not mixed across renal and ureteric stones.

\section{FUNDING}

No funding was received from any organization.

\section{RESULTS}

The search criteria shown above yielded 6,478 studies. We narrowed this down further to only English

TABLE 1 Technological Advances in Stone Clearance

\begin{tabular}{|c|c|c|c|c|c|c|}
\hline 1980 & 1982 & 1983 & 1995 & 2001 & 2005 & 2016 \\
\hline $\begin{array}{l}\text { Rigid } \\
\text { ureteroscope }{ }^{17}\end{array}$ & $\begin{array}{l}\text { Stone retrieval } \\
\text { baskets }{ }^{18} \\
\text { First ureteroscopy } \\
\text { for stone removal }\end{array}$ & $\begin{array}{l}\text { Flexible } \\
\text { ureteroscope }^{19}\end{array}$ & $\begin{array}{l}\text { Holmium } \\
\text { laser clinical } \\
\text { use }^{20}\end{array}$ & $\begin{array}{l}\text { Safe use } \\
\text { of access } \\
\text { sheath }^{21}\end{array}$ & $\begin{array}{l}\text { Digital } \\
\text { ureteroscope }^{22}\end{array}$ & $\begin{array}{l}\text { Single-use } \\
\text { Flexible } \\
\text { ureteroscope }^{23}\end{array}$ \\
\hline
\end{tabular}

J Endolum Endourol Vol 2(4):e44-e50 December 23, 2019.

This article is distributed under the terms of the Creative Commons Attribution-Non

Commercial 4.0 International License. (C) Subramonian et al. 
papers with prospective study design on renal stones published between 1994-2019 with a sample size of 50 or more. In total, we selected 16 papers to review in detail with a total of 1,689 patients. Mean stone clearance across these papers was $80 \%$, and median stone size was $11.0 \mathrm{~mm}$.

Table 2 provides an overview of the 16 papers reviewed in this study, including the number of patients, stone clearance, stone detection method and stone-free cut off size.

Stone clearance was determined by CT scan in 8 studies, $\mathrm{x}$-ray alone in 3 studies, $\mathrm{x}$-ray and ultrasound in 3 studies and 2 studies did not mention how they determined stone clearance.

\section{Stone Detection Method and Clearance}

Figure 1 (page below) demonstrates stone clearance rate plotted against the method of stone detection and shows that when CT scan used to check stone clearance, the clearance rate is lower when compared to other methods such as $\mathrm{x}$-ray. These findings are replicated by Portis et $\mathrm{al}^{13}$, who report that CT is a more sensitive method of detecting stones (and smaller fragments), thus using CT yields a lower stone clearance rate as more of the smaller fragments are visualized.

\section{Stone Cutoff size and Clearance}

The cut-off size used to define the stone-free rate after ureteroscopy also varied, as demonstrated in Table 3. Seven studies did not define whether they used any specific size to define stone clearance. Of these 7 studies, 4 used x-ray to check stone clearance, 1 study used CT scan, and 2 did not mention the method used to detect stone clearance. For studies that used absolute clearance with no residual stones, average clearance was $52 \%$.

Table 3 demonstrates that as the cut-off size used to determine the stone-free rate increased, the stone

TABLE 2 Overview of Studies Reviewed in This Paper

\begin{tabular}{|c|c|c|c|c|}
\hline Author & No. of Patients & $\begin{array}{c}\text { Stone } \\
\text { Clearance (\%) }\end{array}$ & $\begin{array}{l}\text { Detection } \\
\text { Method }\end{array}$ & $\begin{array}{l}\text { Stone Free } \\
\text { Cut-off size }\end{array}$ \\
\hline Lebentrau S, Müller PF, Miernik A et al. ${ }^{1}$ & 307 & 68.7 & $\begin{array}{c}\text { NM (not } \\
\text { mentioned) }\end{array}$ & NM \\
\hline Zhang H, Hong TY, Li G et al. ${ }^{2}$ & 60 & 92 & $\begin{array}{c}\text { x-ray, US } \\
\text { (ultrasound) }\end{array}$ & NM \\
\hline Zhou R, Han C, Hao L et al. ${ }^{3}$ & 192 & 80.7 & CT scan & $<2 \mathrm{~mm}$ \\
\hline Jiang K, Chen H, Yu X et al. ${ }^{4}$ & 58 & 79.3 & CT scan & $<4 \mathrm{~mm}$ \\
\hline Bozzini G, Verze P, Arcaniolo D et al. ${ }^{5}$ & 207 & 82.1 & $\mathrm{x}$-ray & NM \\
\hline Kandemir A, Guven S, Balasar M et al. ${ }^{6}$ & 30 & 86.7 & CT scan & NM \\
\hline Geavlete P, Saglam R, Georgescu D et al. ${ }^{7}$ & 66 & 89.4 & NM & NM \\
\hline Ding J, Xu D, Cao Q et al. ${ }^{8}$ & 180 & 76.7 & CT scan & $<4 \mathrm{~mm}$ \\
\hline Gao X, Zeng G, Chen H et al. ${ }^{9}$ & 135 & 95 & $\mathrm{x}$-ray & NM \\
\hline Sener NC, Bas O, Sener E et al. ${ }^{10}$ & 50 & 92 & CT scan & $<3 \mathrm{~mm}$ \\
\hline Kumar A, Vasudeva P, Nanda B et al. ${ }^{11}$ & 98 & 78.3 & $\mathrm{x}$-ray & $<3 \mathrm{~mm}$ \\
\hline Sener NC, Imamoglu MA, Bas O et al. ${ }^{12}$ & 70 & 100 & x-ray, US & $<3 \mathrm{~mm}$ \\
\hline Portis AJ, Rygwall R, Holtz C et al. ${ }^{13}$ & 69 & 54 & CT scan & $\begin{array}{c}<0 \text { : absolute } \\
\text { stone clearance }\end{array}$ \\
\hline Pearle MS, Lingeman JE, Leveillee R et al. ${ }^{14}$ & 35 & 50 & CT scan & NM \\
\hline Grasso M, Ficazzola $\mathrm{M}^{15}$ & 73 & 76 & CT scan & $<2 \mathrm{~mm}$ \\
\hline Tawfiek ER, Bagley DH ${ }^{16}$ & 59 & 79.7 & x-ray, US & $<3 \mathrm{~mm}$ \\
\hline
\end{tabular}


FIG. 1 Stone clearance rate vs method of stone detection.

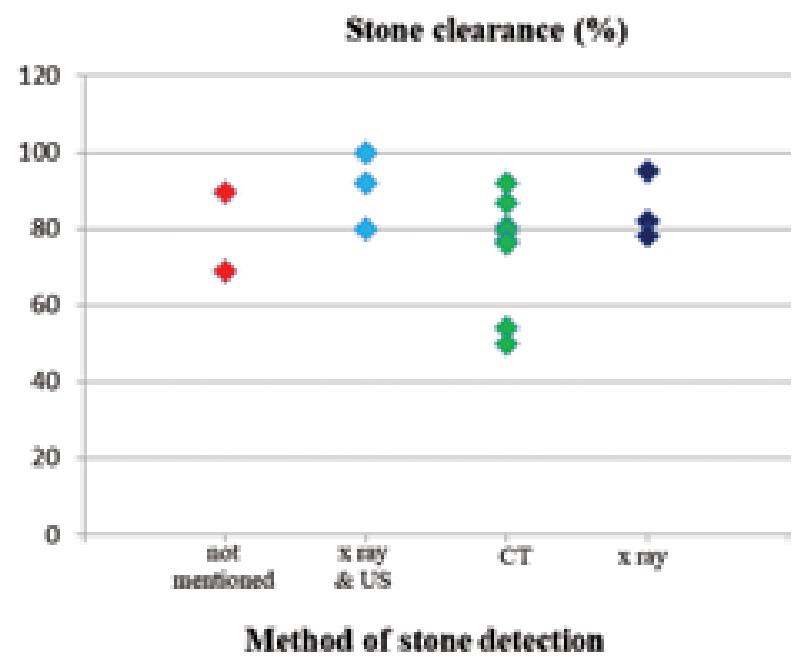

clearance rate decreased, which is as expected. As different papers use different cut-off criteria, it was difficult for us to control for this factor when analyzing stone clearance rates.

\section{Stone clearance and Impact factor of Journal}

We performed a correlation analysis on the relationship between stone clearance rate and the impact factor of the journal in which the paper was published in. We found that there is a negative correlation between the impact factor of the journal in which the paper was published and the stone clearance rate $(\mathrm{r}=-.795, \mathrm{n}=6, \mathrm{p}=0.059)$.

Although it is difficult to conclude this correlation, there is a suggestion that journals with higher impact factors tend to insist on rigorous methodology for assessing stone clearance and this could have resulted in the negative correlation.

TABLE 3 Stone Clearance Rate for Each Cutoff Size Used

\begin{tabular}{|c|c|}
\hline Cut-off Size $\mathbf{( m m )}$ & Stone Clearance Rate $\mathbf{( \% )}$ \\
\hline 0 (absolute clearance) & 52 \\
\hline 2 & 78.35 \\
\hline 3 & 90.56666667 \\
\hline 4 & 78 \\
\hline 5 & 84.6 \\
\hline
\end{tabular}

\section{Stone Clearance and Stone Size Treated}

We performed a correlation analysis between the stone clearance and the median stone size treated. Interestingly, there is a positive correlation between larger stone size and higher clearance rate $(\mathrm{r}=+.155$, $\mathrm{n}=16, \mathrm{p}=0.568$ ). This finding is difficult to explain as one would expect a lower clearance as the stone size increased. This could be partly due to different methods to assess stone clearance and the different sampling across the different studies and the association is weak with no statistical significance.

\section{Stone Clearance Over the Study Period}

We analyzed stone clearance rates over time, between 1994 and 2019, as illustrated in Figure 2. As you can see from the graph, there is a cluster of studies from 2012-2017 with an average stone clearance rate of $84 \%$. We compare this to the studies before 2012 with an average stone clearance of $65 \%$. We did a statistical analysis using an independent sample t-test comparing the stone clearance between these two groups.

Although there is a difference in stone clearance between the 2 groups (the first group is 1994-2011 and the second group is 2012-2019), it was not statistically significant $(p=0.11)$. It is worth noting that out of four studies from the first group, three of them used a post-operative CT scan to determine stone clearance whereas less than half of the twelve studies in the second group used CT scan to determine stone clearance which could account for the difference

J Endolum Endourol Vol 2(4):e44-e50 December 23, 2019.

This article is distributed under the terms of the Creative Commons Attribution-Non

Commercial 4.0 International License. (c) Subramonian et al. 
FIG. 2 Stone clearance rate over time.

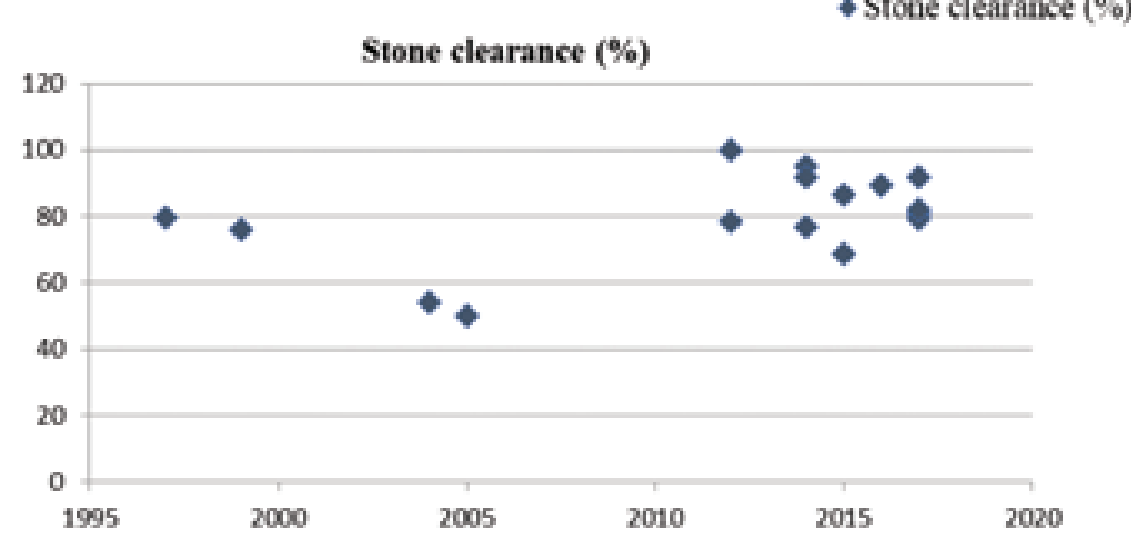

between the two groups. Advances in technology and training would account for some of the improvement in stone clearance as well.

We expect that as the quality of our scopes and lasers have improved (as evidenced by the technological advances in Table 1), the complexity of the stone may also have increased which may mean that overall clearance rates don't look any different.

\section{DISCUSSION}

As shown in Figure 2, stone clearance rate has largely fluctuated since 2012. The rates of stone clearance reported varying significantly across different papers from the same time and different countries. Portis et $\mathrm{al}^{13}$ describe how stone clearance rates differ significantly depending on the cut-off size used to determine 'stone-free rate'. For example, they show that a true stone-free rate ( 0 stones) gives a stone clearance rate of $54 \%$, whereas a stone-free cut-off below $2 \mathrm{~mm}$ gives a higher stone clearance rate of $84 \%$ and finally a stone-free cut-off below $4 \mathrm{~mm}$ gives a stone clearance rate of $95 \%$. Though there is no universal definition of stone-free status, stone clearance is typically considered to be the absence of stones and residual fragments $<4 \mathrm{~mm} .{ }^{24}$ Another important point to appreciate is that historically small residual stones were felt to be insignificant whereas now it is recognized that these small stones will grow and become significant, causing symptoms.

Reddy et $\mathrm{al}^{25}$ discuss some of the factors that are important in maximising stone-free rates post ureteroscopy. One of these factors is determining which patients are appropriate for ureteroscopy (the most important factors for determining this are stone burden and location). Stone-free rate can also be optimized with medical expulsive therapy such as Tamsulosin or by using anti-retropulsion devices. Placing the patient into a flank position can also help support stone migration into a more favourable position for removal. Bağc1oğlu et $\mathrm{al}^{26}$ discuss the management of residual stone fragments and also report the benefit of using adjuvant medical therapy such as Tamsulosin, as well as a healthy diet and regular exercise to prevent stone growth and recurrence. However, more data are needed to look at long-term outcomes after uretoroscopy as small stone fragments that are considered insignificant in short-term studies can lead to stone growth and recurrence in the future.

Portis et al also describe how their stone-free rates as reported by $\mathrm{CT}$ are much lower than stone-free rates reported by $\mathrm{X}$-ray as $\mathrm{CT}$ is a more sensitive method of detecting renal stones, thus decreasing the stone clearance rate. This is replicated in our results as Figure 1 shows that stone clearance rates are much higher when detected by x-ray alone when compared to $\mathrm{CT}$ detection.

A review by Ghani et $\mathrm{al}^{27}$ showed similar factors influencing stone-free rates as reported in our study. In addition to stone size and imaging modality, this paper showed that the location of the stone in the lower pole and use of baskets to retrieve the stones affected stone-free rates as well. 
Upon reviewing papers in this study, we included Pearle et al.'s 2005 paper ${ }^{14}$ despite its smaller sample size. Pearle et al reported that stone clearance rates are much lower in patients followed up by CT compared to x-ray, and they highlight the importance of identifying and including even small stone fragments when reporting stone clearance rate.

Grasso and Ficazzola's paper ${ }^{15}$ from 1999 is one of the earliest papers assessing ureteroscopy for stone removal and stone clearance rates. They report similar findings as well, showing that if the initial stone size was smaller, then the stone clearance rates are higher and they deemed $2 \mathrm{~mm}$ or smaller to be an acceptable standard for stone clearance.

\section{LIMITATIONS}

In our review, we were limited by the various sample sizes of each paper (heterogeneous sampling) from different health care settings. There will also be differences in the competence of the healthcare providers and review of the literature over 25 years. We also could not control for the change in modality of post-operative imaging over time. For example, earlier imaging included small simple stones treated by $\mathrm{x}$-ray but now there are bigger more complex stones and post-operative CT scans.

\section{RECOMMENDATIONS}

We recommend that in the future, a systematic review should be conducted to appraise the available data and to perform trend analysis to be able to assess the difference in stone clearance. Following this, recommendations can be made about a universal stone-free rate that can be used for future studies so that stone clearance rates will be reported more reliably and consistently. When it comes to imaging modalities used post-operatively, in the future, we postulate that ultra-low-dose CT scans can be used where the radiation dose is similar to $\mathrm{x}$ rays. Thus, in the future, we will be able to report accurate stonefree rates with $\mathrm{CT}$ but with lower radiation burdens.

\section{CONCLUSION}

This study highlights that the stone clearance rate after ureteroscopy varies between different publications.
On analysis of the average stone clearance over time, we found that that stone clearance was lower in the papers from 1994 to 2011. However, this was not statistically significant. This difference could be due to stringent criteria and $\mathrm{CT}$ imaging used to define stone clearance in the papers from this period. The factors affecting the published stone clearance rates are average stone size treated, the definition of residual stone size and the method used to determine stone clearance. We recommend that a systematic review should be conducted, performing trend analysis to assess variation in stone clearance and to set a universal cut-off size for a stone-free rate for different imaging modalities.

\section{REFERENCES}

1. Lebentrau S, Müller P, Miernik A, et al. Risk factors for ureteral damage in ureteroscopic stone treatment: Results of the German Prospective Multicentre Benchmarks of Ureterorenoscopic Stone Treatment-Results in Terms of Complications, Quality of Life, and Stone-Free Rates Project Urol Int 2018;102(2):187-93. https://www.ncbi .nlm.nih.gov/pubmed/30481771

2. Zhang H, Hong T, Li G, Jiang N, Hu C, Cui X et al. Comparison of the efficacy of ultra-mini PCNL, flexible ureteroscopy, and shock wave lithotripsy on the treatment of 1-2 cm lower pole renal calculi. Urol Int 2018;102(2):153-59. https://www.ncbi.nlm.nih.gov/ pubmed $/ 30352443$

3. Zhou R, Han C, Hao L et al. Ureteroscopic lithotripsy in the Trendelenburg position for extracting obstructive upper ureteral obstruction stones: a prospective, randomized, comparative trial. Scand J Urol 2018;52(4):291-95. https://www.ncbi.nlm.nih.gov/pubmed/30334631

4. Jiang $\mathrm{K}$, Chen $\mathrm{H}, \mathrm{Yu} \mathrm{X}$ et al. The "all-seeing needle" micro-PCNL versus flexible ureterorenoscopy for lower calyceal stones of $\leq 2 \mathrm{~cm}$. Urolithiasis 2018;47(2):201-206. https://www.ncbi.nlm.nih.gov/ pubmed $/ 29497768$

5. Bozzini G, Verze P, Arcaniolo D et al. A prospective randomized comparison among SWL, PCNL and RIRS for lower calyceal stones less than $2 \mathrm{~cm}$ : a multicenter experience: A better understanding on the treatment options for lower pole stones. World J Urol 2017;35(12):1967-75. https://www.ncbi.nlm.nih.gov/ pubmed/28875295

J Endolum Endourol Vol 2(4):e44-e50 December 23, 2019.

This article is distributed under the terms of the Creative Commons Attribution-Non

Commercial 4.0 International License. () Subramonian et al. 
6. Kandemir A, Guven S, Balasar M et al. A prospective randomized comparison of micropercutaneous nephrolithotomy (Microperc) and retrograde intrarenal surgery (RIRS) for the management of lower pole kidney stones. World J Urol 2017;35(11):1771-76. https://www.ncbi.nlm.nih.gov/pubmed/28589217

7. Geavlete P, Saglam R, Georgescu D et al. Robotic flexible ureteroscopy versus classic flexible ureteroscopy in renal stones: the initial Romanian Experience. Chirurgia 2016;111(4):326-9. https://www.ncbi.nlm .nih.gov/pubmed/27604670

8. Ding J, Xu D, Cao Q et al. Comparing the efficacy of a multimodular flexible ureteroscope with its conventional counterpart in the management of renal stones. Urology 2015;86(2):224-9. https://www.ncbi.nlm.nih .gov/pubmed/26169008

9. Gao X, Zeng G, Chen H et al. A Novel ureterorenoscope for the management of upper urinary tract stones: initial experience from a prospective multicenter study. $\mathrm{J}$ Endourol 2015;29(6):718-24. https://www.ncbi.nlm .nih.gov/pubmed/25668137

10. Sener NC, Bas O, Sener E et al. Asymptomatic lower pole small renal stones: shock wave lithotripsy, flexible ureteroscopy, or observation? A prospective randomized trial. Urology 2015;85(1):33-7. https://www.ncbi.nlm .nih.gov/pubmed/25440816

11. Kumar A, Vasudeva P, Nanda B et al. A Prospective Randomized comparison between shock wave lithotripsy and flexible ureterorenoscopy for lower caliceal stones $\leq 2 \mathrm{~cm}$ : a single-center experience. J Endourol 2015;29(5):575-9. https://www.ncbi.nlm.nih.gov/ pubmed/25203489

12. Sener NC, Imamoglu MA, Bas O et al. Prospective randomized trial comparing shock wave lithotripsy and flexible ureterorenoscopy for lower pole stones smaller than $1 \mathrm{~cm}$. Urolithiasis 2014;42(2):127-31. https://www.ncbi.nlm.nih.gov/pubmed/24220692

13. Portis A, Rygwall R, Holtz C, Pshon N, Laliberte M. Ureteroscopic Laser lithotripsy for upper urinary tract calculi with active fragment extraction and computerized tomography followup. J Urol 2006;175(6):2129-34.

14. Pearle MS, Lingeman JE, Leveillee $\mathrm{R}$ et al. Prospective, randomized trial comparing shock wave lithotripsy and ureteroscopy for lower pole caliceal calculi $1 \mathrm{~cm}$ or less. J Urol 2005;173(6):2005-9. https://www.ncbi .nlm.nih.gov/pubmed/16697818
15. Grasso M, Ficazzola M. Retrograde ureteropyeloscopy for lower pole caliceal calculi. J Urol 1999;162(6):1904-8. https:/www.ncbi.nlm.nih.gov/pubmed/15879805

16. Tawfiek ER, Bagley DH. Management of upper urinary tract calculi with ureteroscopic techniques. Urology 1999;53(1):25-31. https://www.ncbi.nlm.nih.gov/ pubmed/9886583

17. Pérez-Castro Ellendt E, Martinez-Piñero J. Ureteral and renal endoscopy. Eur Urol 1982;8(2):117-20.

18. Dormia E. Dormia basket: Standard technique, observations, and general concepts. Urology. 1982;20(4):437. https:// www.goldjournal.net/article/0090-4295(82)90476-9/pdf

19. Bagley DH, Huffman JL, Lyon ES. Combined rigid and flexible ureteropyeloscopy. J Urol 1983;130:243-4. https://www.ncbi.nlm.nih.gov/pubmed/6876267

20. Denstedt JD, Razvi HA, Sales JL et al. Preliminary experience with holmium:YAG laser lithotripsy. J Endourol 1995;9(3):255. https://www.ncbi.nlm.nih .gov/pubmed/7550269

21. Monga M, Bhayani S, Landman J et al. Ureteral access for upper urinary tract disease: the access sheath. J Endourol 2001;15(8):831-4. https://www.ncbi.nlm .nih.gov/pubmed/11724124

22. Springhart WP, Maloney ME, Sur RL, et al. Digital video ureteroscope: a new paradigm in ureteroscopy. J Urol 2005;173(Suppl 4):428

23. Proietti S, Dragos L, Molina W et al. Comparison of new single-use digital flexible ureteroscope versus nondisposable fiber optic and digital ureteroscope in a cadaveric model. J Endourol 2016;30:655-59. https:// www.ncbi.nlm.nih.gov/pubmed/27084572

24. Ozdedeli K, Cek M. Residual fragments after percutaneous nephrolithotomy. Balkan Med J. 2012;29(3):230-35. https:/www.ncbi.nlm.nih.gov/pmc/articles/PMC4115827/

25. Reddy TG, Assimos DG. Optimizing stone-free rates with ureteroscopy. Rev Urol 2015;17(3):160-64. https:// www.ncbi.nlm.nih.gov/pmc/articles/PMC4633659/

26. Bağcioğlu M, Özcan S, Karadağ MA et al. Prognosis of clinically insignificant residual renal stone fragments following therapy with minimally invasive techniques. Kafkas J Med Sci 2015;5(2):70-74. https://pdfs .semanticscholar.org/7d67/d0acad5f8e24e8d8cdfe446a59849ef8a3d6.pdf

27. Ghani K, Wolf J. What is the stone-free rate following flexible ureteroscopy for kidney stones? Nat Rev Urol 2015;12(5):281-88. https://www.ncbi.nlm.nih.gov/ pubmed $/ 25868563$

J Endolum Endourol Vol 2(4):e44-e50 December 23, 2019.

This article is distributed under the terms of the Creative Commons Attribution-Non Commercial 4.0 International License. (c) Subramonian et al. 